\title{
Usulan Strategi Promosi untuk Meningkatkan Penjualan di PT. Antar Putra Motor, Bandung Barat
}

\author{
Proposed Promotion Strategy to Increase Sales \\ at PT. Antar Putra Motor, West Bandung
}

\author{
Firdhan Mezzalundi, Yulianti \\ Program Studi Teknik Industri Universitas Kristen Maranatha, Bandung \\ E-mail: firdhanmezzalundi@gmail.com, yulianti@eng.maranatha.edu
}

\begin{abstract}
Abstrak
PT. Antar Putra Motor merupakan dealer resmi Yamaha yang telah berdiri sejak 1993. Beberapa tahun terakhir terjadi penurunan penjualan walaupun pihak perusahaan telah meningkatkan biaya promosinya. Penelitian ini bertujuan memberikan usulan strategi promosi yang tepat bagi perusahaan untuk meningkatkan penjualan.

Pengumpulan data dilakukan dengan cara menyebarkan kuesioner yang mengacu pada model Bauran Promosi dan teori segmentasi-targeting-positioning. Kuesioner penelitian disebarkan pada 100 orang responden usia minimal 17 tahun yang sudah mengetahui promosi yang dilakukan perusahaan.

Data tingkat kepentingan divalidasi menggunakan metode Analisis Faktor sehingga menyisakan 6 variabel. Data tingkat kepentingan dan kinerja bauran promosi dari keenam variabel tersebut diolah menggunakan metode Importance Performance Analysis dan uji hipotesis rata-rata. Informasi mengenai profil konsumen digunakan untuk usulan targeting dan mempertajam usulan penelitian.

Hasil penelitian menyarankan perusahaan untuk melakukan penelitian lebih lanjut mengenai pemilihan warna dan kekontrasan untuk media cetak brosur, memilih kualitas kertas brosur yang baik, menggunakan kata-kata yang unik/lucu bagi orang dewasa atau kata berbahasa Sunda, menyiapkan karyawan khusus yang menangani kunjungan perusahaan, menyesuaikan periode cash back dengan masa panen petani, memperbesar diskon untuk pembelian tunai, bekerjasama dengan bank untuk diskon, menyiapkan SPG dengan informasi tentang motor yang dijualnya, serta menginformasikan acara promosi melalui brosur/radio RRI/radio Elshinta/acara pameran/car free day.
\end{abstract}

Kata kunci: Bauran promosi, analisis faktor, importance-performance analysis, pengujian hipotesis

Abstract
PT. Antar Putra Motor is an official Yamaha dealer that established since 1993. In recent years there has been a decline in sales even though the company has increased its promotion costs. This study aims to provide a promotion strategy proposal that is right for the company to increase sales.

Questionnaires refers to Promotion Mix model and segmentation-targeting-positioning theory. The research questionnaire distributed to 100 respondents aged at least 17 years who knew about company's promotion.

Consumer's importance level validated using the Factor Analysis method, leaving 6 variables. The importance level data and promotion mix performance of the six variables processed using Importance-Performance Analysis method and hypothesis testing for means. Information about consumer profiles used for proposed targeting and sharpen the research proposals.

Research results recommend company to conduct further research regarding color selection and contrast for brochure media, choosing good quality brochure paper, using unique/funny words for adults or Sundanese words, preparing special employees who handle company visits, adjusting cash back period with the harvest period of farmers, greater discounts for cash purchases, cooperate with banks for discounts, prepare SPG with information about the motorcycles, and inform promotion events through brochures/RRI radio/Elshinta radi lexhibition even /car free day.

Keywords: Promotion Mix, factor analysis, importance-performance analysis, hypothesis testing 


\section{Pendahuluan}

Persaingan antar perusahaan yang menawarkan produk serupa memaksa setiap perusahaan untuk menjalin hubungan dan komunikasi yang lebih baik dengan pelanggan, sehingga informasi mengenai perusahaan dapat diterima oleh pelanggan dan pada akhirnya akan menguntungkan perusahaan. Promosi merupakan salah satu cara perusahaan untuk berkomunikasi dengan pelanggan. Dengan berbagai macam bentuk dan media promosi, kegiatan promosi perlu direncanakan dan dijalankan dengan baik agar memberikan hasil yang optimal.

PT. Antar Putra Motor merupakan sebuah dealer resmi Yamaha yang bergerak dibidang penjualan sepeda motor, suku cadang, dan bengkel, yang berpusat di Jl. Raya Lembang no. 200. Sejak awal berdiri, PT. Antar Putra Motor telah berkembang hingga memiliki beberapa cabang dealer sepeda motor. Sebagai dealer, perusahaan aktif melakukan kegiatan-kegiatan promosi dalam upayanya meningkatkan penjualan produk dan jasanya.

Beberapa tahun terakhir terjadi penurunan penjualan pada PT. Antar Putra Motor sebesar 17,4\%, walaupun biaya promosi yang sudah dikeluarkan oleh perusahaan meningkat setiap tahunnya. Pihak perusahaan perlu mengetahui strategi promosi yang tepat bagi peningkatan penjualannya berdasarkan faktor-faktor yang dipentingkan oleh konsumen dalam promosi dan juga berdasarkan penilaian konsumen terhadap promosi yang telah dilakukan oleh PT. Antar Putra Motor.

\section{Tinjauan Pustaka}

Tinjauan pustaka ini berisi teori-teori yang digunakan dalam penelitian, yang dijadikan dasar kerangka berpikir dan landasan dalam pengolahan data serta penganalisaan hasil pengolahan data.

\subsection{Bauran Promosi (Kotler, 1997)}

Kegiatan promosi adalah salah satu bagian dari bauran pemasaran perusahaan, yang isinya memberikan informasi kepada masyarakat atau konsumen tentang produk atau jasa yang ditawarkan perusahaan. Tidak hanya itu, kegiatan promosi merupakan kegiatan komunikasi antara perusahaan dengan pelanggan atau konsumen. Perusahaan berharap dengan dilaksanakannya kegiatan promosi secara berkesinambungan dan terarah akan mampu mencapai hasil penjualan dan keuntungan yang maksimal.

Bauran promosi menurut Philip Kotler yang tercantum adalah sebagai berikut :

1. Periklanan (Advertising)

Periklanan adalah semua bentuk penyajian nonpersonal, promosi ide-ide, promosi barang atau jasa yang dilakukan oleh sponsor yang dibayar, dengan sifat - sifat berikut:

a. Presentasi umum: cara komunikasi yang sangat umum.

b. Tersebar luas: berdaya sebar luas yang memungkinkan penjual mengulang satu pesan berkali-kali. Periklanan berskala besar oleh seorang penjual menunjukkan sesuatu yang positif tentang ukuran, kekuatan, dan keberhasilan penjual.

c. Ekspresi yang lebih kuat: melalui penggunaan cetakan, suara, dan warna yang penuh seni.

d. Tidak bersifat pribadi: Audiens tidak merasa wajib memperhatikan atau menanggapi. Iklan hanya mampu melakukan monolog, bukan dialog, dengan audiens.

2. Promosi Penjualan (Sales Promotion), adalah variasi insentif jangka pendek untuk merangsang pembelian atau penjualan suatu produk atau jasa. Dimana semuanya terdapat tiga manfaat yang berbeda:

a. Komunikasi: menarik perhatian dan biasanya memberikan informasi yang dapat mengarahkan konsumen kepada produk.

b. Insentif: menggabungkan sejumlah kebebasan, dorongan, atau kontribusi yang memberi nilai bagai konsumen.

c. Ajakan: merupakan ajakan untuk melakukan transaksi pembelian sekarang.

Promosi penjualan menciptakan tanggapan yang lebih kuat dan lebih cepat untuk mendramatisasi penawaran produk dan mendorong penjualan yang lesu. Namun, pengaruh promosi penjualan biasanya bersifat jangka pendek, dan tidak efektif dalam membangun preferensi merek jangka panjang. 
3. Hubungan masyarakat dan Publisitas

Daya tarik hubungan masyarakat dan publisitas didasarkan pada tiga sifat khusus:

a. Kredibilitas tinggi: berita dan gambar lebih otentik dan dipercaya oleh pembaca dibandingkan dengan iklan.

b. Kemampuan menangkap pembeli yang tidak menduga: hubungan masyarakat dapat menjangkau banyak calon pembeli yang cenderung menghindari wiraniaga dan iklan karena pesan diterima oleh pembeli lebih sebagai berita, bukan sebagai komunikasi bertujuan penjualan.

c. Dramatisasi: hubungan masyarakat memiliki kemampuan untuk mendramatisasi suatu perusahaan atau produk.

Bauran ini cenderung kurang digunakan oleh perusahaan, namun jika program hubungan masyarakat dan publisitas ini direncanakan dan dikoordinasikan dengan baik akan dapat sangat efektif. Contoh jamuan makan, konfrensi pers dan lain-lain.

4. Penjualan Personal (Personal Selling)

Adalah alat yang paling efektif, terutama dalam membangun preferensi, keyakinan, dan tindakan pembeli, dengan manfaat:

a. Konfrontasi personal: interaksi antara 2 orang atau lebih. Kedua pihak dapat melihat kebutuhan dan karakteristik pihak lain secara lebih dekat dan segera melakukan penyesuaian.

b. Memperat: wiraniaga yang efektif harus terus berupaya mengutamakan kepentingan pelanggannya agar dapat mempertahankan hubungan.

c. Tanggapan: pembeli merasa merasa berkewajiban untuk mendengarkan/menanggapi pembicaraan wiraniaga.

5. Pemasaran Langsung (Direct Marketing). Komunikasi secara langsung melalui e-mail atau internet untuk mendapatkan tanggapan langsung dari konsumen secara jelas. Pemasaran langsung memiliki empat karakteristik:

a. Nonpublik: pesan biasanya ditujukan kepada orang tertentu.

b. Disesuaikan: pesan dapat disesuaikan untuk menarik orang yang dituju.

c. Terbaru: suatu pesan dapat disiapkan dengan sangat cepat untuk diberikan kepada seseorang.

d. Interaktif: pesan dapat diubah tergantung pada tanggapan orang tersebut.

\subsection{Analisis Faktor (Hair, 2006)}

Analisis Faktor adalah teknik interdependence yang sering digunakan karena adanya kebutuhan untuk meningkatkan pengetahuan mengenai struktur dan hubungan antara variabel-variabel. Metode ini memiliki tujuan utama untuk mempelajari pola atau hubungan yang mendasari variabel dalam jumlah banyak dan untuk memperkirakan apakah informasi tersebut dapat dipadatkan atau dirangkum dalam bentuk faktor/komponen yang lebih kecil, dengan cara mendefinisikan variabelvariabel yang saling berkorelasi tinggi namun kehilangan informasi seminimum mungkin. Faktorfaktor yang baru terbentuk ini diasumsikan akan menggambarkan dimensi data. Jika peneliti berfokus pada reduksi jumlah variabel, maka dimensi tersebut dapat menjadi panduan untuk membentuk jumlah faktor yang baru.

Analisis Faktor digunakan untuk:

1. Penelitian ekspolatori: bila Analisis Faktor digunakan sebagai metode untuk mereduksi variabel.

2. Penelitian konfirmatori: bila Analisis Faktor digunakan untuk pengujian hipotesis, variabel mana yang harus dikelompokan sebagai faktor atau jumlah faktor yang tepat.

\subsection{Pengujian Hipotesis Rata-rata (Anderson, 2008)}

Uji hipotesis merupakan prosedur untuk pengambilan keputusan secara statistika, untuk memutuskan apakah menerima atau menolak hipotesis mengenai parameter yang telah dirumuskan. Salah satu bentuk pengujian hipotesis adalah pengujian hipotesis rata-rata dari 2 populasi independen. 
$\mathrm{H}_{\mathrm{o}}: \mu_{1}=\mu_{2}$

$\mathrm{H}_{1}: \mu_{1} \neq \mu_{2} \quad$ atau $\quad \mu_{1}>\mu_{2} \quad$ atau $\quad \mu_{1}<\mu_{2}$

Rumus yang digunakan :

$\mathrm{Z}=\frac{\left(\overline{\mathrm{x}}_{1}-\overline{\mathrm{x}}_{2}\right)-\left(\mu_{1}-\mu_{2}\right)}{\sqrt{\frac{\mathrm{s}_{1}^{2}}{\mathrm{n}_{1}}+\frac{\mathrm{s}_{2}^{2}}{\mathrm{n}_{2}}}}$

Dimana :

$\mu$ : rata-rata populasi

$\mathrm{x}$ : rata-rata sampel

$\mathrm{s}:$ standard deviasi sampel

$\mathrm{n}$ : ukuran sampel

\subsection{Importance Performance Analysis (Supranto, 2001)}

Metode Importance Performance Analysis bertujuan untuk mengukur hubungan antara persepsi konsumen dan prioritas peningkatan kualitas produk/jasa. Analisis perbandingan performance (yang menunjukan kinerja suatu perusahaan atau produk) dengan importance (yang menunjukan harapan responden yang terkait dengan variabel yang diteliti) digambarkan dalam diagram kartesius, membentuk suatu bangun yang dibagi menjadi empat bagian yang dibatasi oleh dua buah garis yang berpotongan tegak lurus pada titik $(\mathrm{x}, \mathrm{y})$.

Sumbu x menunjukkan rata-rata dari rata-rata performansi dari produk atau perusahaan terhadap suatu variabel dan sumbu y menunjukkan rata-rata dari tingkat kepentingan suatu variabel. Tiap kuadran menggambarkan terjadinya suatu kondisi yang berbeda dengan kuadran lainnya.

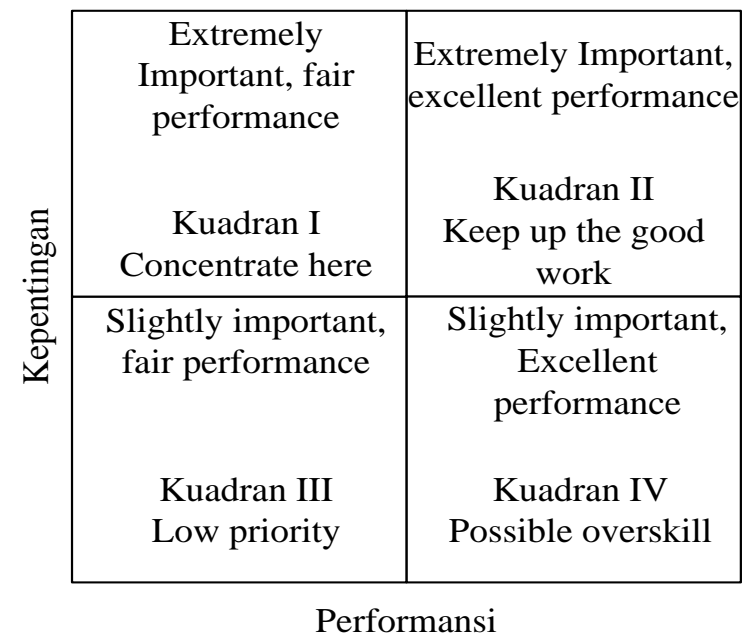

Gambar 1. Matrix Importance Performance Analysis

Keterangan:

I : Prioritas Utama

Faktor-faktor yang terletak pada kuadran ini dianggap sebagai yang penting oleh konsumen namun kondisi pada saat ini belum memuaskan sehingga pihak pengelola berkewajiban mengalokasikan sumber daya yang memadai untuk meningkatkan kinerja berbagai faktor tersebut

II : Pertahankan Prestasi

Faktor-faktor yang terletak pada kuadran ini dianggap penting sebagai faktor penunjang bagi kepuasan konsumen sehingga pihak pengelola berkewajiban memastikan bahwa kinerja dari usaha yang dikelola dapat terus dipertahankan 
III : Prioritas Rendah

Faktor-faktor yang terletak pada kuadran ini mempunyai tingkat kepuasan yang rendah dan sekaligus tidak dianggap terlalu penting bagi konsumen, sehingga pihak pengelola tidak perlu memprioritaskan pada factor-faktor tersebut.

IV : Berlebihan

Faktor-faktor yang terletak pada kuadran ini dianggap tidak terlalu penting sehingga pihak pengelola perlu mengalokasikan sumber daya untuk factor-faktor tersebut kepada faktor-faktor

\section{Pembahasan}

\subsection{Penentuan Variabel Penelitian}

Untuk dapat merancang strategi promosi yang tepat, disusun variabel penelitian berdasarkan teori Bauran Promosi yang telah dilakukan perusahaan, sebagai berikut :

(1) Periklanan

Var 1 : Keterkinian Informasi tentang produk di PT. Antar Putra Motor(design, warna, variasi tipe Kendaraan)

Var 2 : Kemenarikan kata - kata yang digunakan di brosur

Var 3 : Kemenarikan kata - kata yang digunakan di radio

Var $4:$ Kemenarikan kata - kata yang digunakan di majalah

Var 5 : Kemenarikan kata - kata yang digunakan di spanduk

Var 6 : Kemenarikan kata - kata yang digunakan di surat kabar / koran

Var 7 : Kemenarikan kata - kata yang digunakan di pamflet

Var 8 : Kemenarikan sound effect / efek suara pada rekaman (Radio)

Var 9 : Kemenarikan sound effect / efek suara saat live dari penyiar (Radio)

Var 10 : Kemenarikan model iklan

Var 11 : Kemenarikan gambar atau ilustrasi ( media cetak)

Var 12 : Kekontrasan warna yang digunakan ( media cetak )

Var 13 : Kejelasan informasi berupa pembayaran Kendaraan beserta cicilannya

Var 14 : Kejelasan informasi tentang spesifikasi Kendaraan

(2) Promosi penjualan

Var 15 : Kemenarikan hadiah dari pembelian produk di PT. Antar Putra Motor

Var 16 : Kemenarikan pajangan dan demonstrasi di tempat penjualan

Var 17 : Keekonomisan penawaran paket harga (ditambah dengan pemberian macam macam merchandise)

Var 18 : Kemenarikan iklan di internet dengan memperlihatkan blog atau halaman web langsung dan media sosial dari PT. Antar Putra Motor

Var 19 : Kelengkapan informasi layanan internet, seperti produk baru, call center, jadwal event-event atau acara, dll.

Var 20 : Kemenarikan dalam menampilkan produk melalui media internet

Var 21 : Kemenarikan pemberian diskon oleh PT. Antar Putra Motor setiap penjualan

Var 22 : Cash back dengan jumlah besar pada pertengahan tahun dan akhir tahun

Var 23 : Jaminan pelayanan yang diberikan oleh PT. Antar Putra Motor setelah pembelian

(3) Humas dan Publisitas

Var 24 : Kemudahan untuk menghubungi call center

Var 25 : Kesempatan yang diberikan oleh PT. Antar Putra Motor untuk melakukan kunjungan Ke PT. Antar Putra Motor

Var 26 : Frekuensi aktivitas layanan publik, seperti menyumbangkan hasil penjualan tiap unit produk untuk pihak tertentu (seperti panti asuhan, anak jalanan, dll.)

(4) Penjualan personal

Var 27 : Kejelasan informasi yang disampaikan oleh salesman.

Var 28 : Ketepatan/waktu tempo kendaraan sampai di tangan konsumen

Var 29 : Frekuensi acara/event yang disponsori oleh perusahaan (seperti konser musik / kontes musik, kegiatan olah raga, kegiatan pameran, dll.)

Var 30 : Variansi jenis motor yang boleh dicoba

Var 31 : Frekuensi konferensi pers di pameran untuk perkenalan produk baru 
Var 32 : Kemenarikan para SPG (Sales Promotion Girl)

Var 33 : Kemampuan SPG (Sales Promotion Girl) untuk menjelaskan produk

Sedangkan untuk tujuan segmentasi, targeting dan positioning disusun pertanyaan berkaitan dengan usia, jenis kelamin, pekerjaan, pendidikan, uang saku/penghasilan, merk motor yang digunakan saat ini, motivasi membeli motor, jenis motor yang diinginkan, cara pembayaran motor, kartu debit dan kartu kredit yang digunakan, besar uang muka dan cicilan pembelian motor, media informasi promosi dan media cetak yang disukai, majalah/koran yang dibaca, media sosial yang digunakan, acara radio dan waktu mendengarkan radio, serta acara pameran atau kegiatan event tentang brand motor yang pernah dikunjungi.

\subsection{Pengumpulan Data}

Data yang digunakan dalam penelitian ini dikumpulkan melalui dua kali penyebaran kuesioner penelitian yang terdiri dari 2 bagian yaitu:

1. Bagian pertama berisi data responden dengan variabel penelitian untuk segmentasi-targetingpositioning.

2. Bagian kedua berisi pengukuran tingkat kepentingan konsumen (skala Likert Sangat Tidak Penting hingga Sangat Penting / 1 hingga 4) dan pengukuran kinerja promosi di PT. Antar Putra Motor menurut konsumen (skala Likert Sangat Tidak Baik hingga Sangat Baik / 1 hingga 4).

Penentuan jumlah sampel minimum kuesioner penelitian menggunakan rumus di bawah:

$\mathrm{n}=\left(\frac{\mathrm{Z}_{\alpha / 2}}{\mathrm{e}}\right)^{2} \cdot \mathrm{P} \cdot(1-\mathrm{P})$

Dimana :

$\mathrm{n}=$ Ukuran sampel.

$\mathrm{Z}=$ nilai dari tabel Normal.

$\mathrm{e}=$ Sampling error maksimum yang diperkenankan

$\alpha=$ Tingkat ketelitian (5\%)

$\mathrm{P}=$ Proporsi populasi yang akan diteliti. Jika tidak dapat memperkirakan proporsi populasi, maka ditentukan $\mathrm{P}=0.5$.

Sehingga :

$\mathrm{N}=\left(\frac{1.96}{0.01}\right)^{2} \cdot 0.5 \cdot(1-0.5)=96.04$ responden $\approx 97$ responden

Jumlah responden minimal adalah 97 responden, namun dengan pertimbangan kemungkinan adanya pengisian kuesioner yang tidak lengkap maka akan disebarkan kuesioner sebanyak 100 kuesioner.

Kuesioner penelitian disebarkan dengan metode sampling Nonprobability Sampling yaitu Purposive Sampling, dengan persyaratan responden berusia minimal 17 tahun, yang sudah mengetahui promosi dealer motor Yamaha PT. Antar Putra Motor. Kuesioner penelitian disebarkan di sekitar Lembang, yaitu di daerah perumahan penduduk, pasar Lembang, pertokoan, serta di sekitar dealer PT. Antar Putra Motor.

\subsection{Pengolahan Kuesioner Penelitian}

\subsubsection{Uji Validitas dengan Analisis Faktor}

Penelitian ini menggunakan metode Analisis Faktor untuk proses validasi. Data yang digunakan adalah data tingkat kepentingan sejumlah 33 variabel. Proses Analisis Faktor dapat dilakukan setelah seluruh variabel memiliki nilai Measure of Sampling Adequacy (MSA) minimal 0.5, MSA keseluruhan minimal 0.5 dan nilai signifikansi Bartlett's Test of Sphericity kurang dari 0.05. Setelah 5 kali pengujian, jumlah variabel yang dapat diproses Analisis Faktor tersisa 13 variabel, yaitu variabel 1, 3, 4, 12, 14, 15, 20, 21, 22, 23, 25, 30, dan variabel 33 . 
Pengolahan Analisis Faktor dibantu dengan software SPSS. Karena pengolahan Analisis Faktor ini bertujuan untuk pengujian validitas mana dipilih jumlah faktor yang terbentuk sejumlah 4, sesuai dengan jumlah dimensi Bauran Promosi yang digunakan. Hasil Total Variance Explained sebagai berikut:

Tabel 1. Total Variance Explained

\begin{tabular}{|c|c|c|c|c|c|c|c|c|c|}
\hline \multirow[b]{2}{*}{ Component } & \multicolumn{3}{|c|}{ Initial Eigenvalues } & \multicolumn{3}{|c|}{ Extraction Sums of Squared Loadings } & \multicolumn{3}{|c|}{ Rotation Sums of Squared Loadings } \\
\hline & Total & $\%$ of Variance & Cumulative \% & Total & $\%$ of Variance & Cumulative \% & Total & $\%$ of Variance & Cumulative $\%$ \\
\hline 1 & 3.481 & 26.778 & 26.778 & 3.481 & 26.778 & 26.778 & 3.157 & 24.286 & 24.286 \\
\hline 2 & 1.999 & 15.375 & 42.152 & 1.999 & 15.375 & 42.152 & 1.682 & 12.935 & 37.221 \\
\hline 3 & 1.472 & 11.323 & 53.475 & 1.472 & 11.323 & 53.475 & 1.623 & 12.488 & 49.709 \\
\hline 4 & 1.103 & 8.488 & 61.963 & 1.103 & 8.488 & 61.963 & 1.593 & 12.254 & 61.963 \\
\hline 5 & .931 & 7.162 & 69.126 & & & & & & \\
\hline 6 & .753 & 5.792 & 74.917 & & & & & & \\
\hline 7 & .702 & 5.399 & 80.316 & & & & & & \\
\hline 8 & .590 & 4.542 & 84.858 & & & & & & \\
\hline 9 & .564 & 4.338 & 89.196 & & & & & & \\
\hline 10 & .507 & 3.900 & 93.096 & & & & & & \\
\hline 11 & .462 & 3.557 & 96.653 & & & & & & \\
\hline 12 & .328 & 2.522 & 99.175 & & & & & & \\
\hline 13 & .107 & .825 & 100.000 & & & & & & \\
\hline
\end{tabular}

Extraction Method: Principal Component Analysis.

Total keempat faktor tersebut dapat menjelaskan $61.963 \%$ variabilitas 13 variabel awal. Berdasarkan kriteria Persentage of Variance Criterion artinya sudah memenuhi syarat karena melebihi $60 \%$.

Di bawah ini adalah hasil rotasi dari factor loading ke 13 variabel yang diolah dengan Analisis Faktor. Rotasi ini dilakukan karena pada tabel Component Matrix sebelumnya, ada ketidakjelasan pengalokasian variabel.

Tabel 2. Rotated Component Matrix

\begin{tabular}{|l|l|l|r|r|}
\hline & \multicolumn{4}{|c|}{ Component } \\
\cline { 2 - 5 } & 1 & 2 & 3 & \multicolumn{1}{c|}{4} \\
\hline VAR14 & .848 & & & \\
VAR33 & .800 & & & \\
VAR3 & .736 & & & \\
VAR23 & .715 & & & \\
VAR15 & .601 & & & \\
VAR1 & & .831 & & \\
VAR22 & & .588 & .415 & \\
VAR21 & & .550 & -.514 & \\
VAR30 & & & .757 & \\
VAR25 & & & .670 & .731 \\
VAR20 & & & & .717 \\
VAR4 & & & & -.560 \\
VAR12 & & & & \\
\hline
\end{tabular}

Berdasarkan Tabel 2 diatas, terlihat jelas pengelompokan variabel ke dalam keempat faktor. Tabel 2 diatas berisi nilai factor loading masing-masing variabel, yang menunjukkan peran masingmasing variabel dalam mendefinisikan tiap faktor.

Berdasarkan dimensi Bauran Promosi, maka pengelompokkan variabelnya dapat dilihat pada Tabel 3. Variabel yang tidak sesuai dengan dimensi Bauran Promosi, tidak digunakan lebih lanjut. 
Tabel 3. Hasil Validasi

\begin{tabular}{|c|c|c|c|}
\hline $\begin{array}{c}\text { Faktor 1: } \\
\text { Penjualan Personal }\end{array}$ & $\begin{array}{c}\text { Faktor 2: } \\
\text { Promosi Penjualan }\end{array}$ & $\begin{array}{c}\text { Faktor 3: } \\
\text { Humas dan Publisitas }\end{array}$ & $\begin{array}{l}\text { Faktor 4: } \\
\text { Periklanan }\end{array}$ \\
\hline \multirow[t]{2}{*}{$\begin{array}{l}\text { Var 33: } \\
\text { Kemampuan SPG } \\
\text { untuk menjelaskan } \\
\text { produk }\end{array}$} & $\begin{array}{l}\text { Var 22: } \\
\text { Cash back dengan } \\
\text { jumlah besar pada } \\
\text { pertengahan tahun dan } \\
\text { akhir tahun }\end{array}$ & $\begin{array}{l}\text { Var 25: } \\
\text { Kesempatan yang } \\
\text { diberikan oleh PT. } \\
\text { Antar Putra Motor } \\
\text { untuk melakukan } \\
\text { kunjungan Ke PT. } \\
\text { Antar Putra Motor }\end{array}$ & $\begin{array}{l}\text { Var 4: } \\
\text { Kemenarikan kata - } \\
\text { kata yang digunakan } \\
\text { di majalah }\end{array}$ \\
\hline & $\begin{array}{l}\text { Var 21: } \\
\text { Kemenarikan } \\
\text { pemberian diskon oleh } \\
\text { PT. Antar Putra Motor } \\
\text { setiap penjualan }\end{array}$ & & $\begin{array}{l}\text { Var 12: } \\
\text { Kekontrasan warna } \\
\text { yang digunakan } \\
\text { (media cetak ) }\end{array}$ \\
\hline
\end{tabular}

3.3.2 Pengolahan Kuesioner Profil Konsumen

Tabel dibawah ini menunjukkan profil responden penelitian ini:

Tabel 4. Profil Konsumen

\begin{tabular}{|c|c|c|}
\hline Profil & Jumlah & Persentase \\
\hline \multicolumn{3}{|l|}{ Usia } \\
\hline Usia $\leq 17$ tahun & 3 & $3 \%$ \\
\hline 17 tahun $<$ Usia $\leq 23$ tahun & 10 & $10 \%$ \\
\hline 23 tahun $<$ Usia $\leq 30$ tahun & 20 & $20 \%$ \\
\hline 30 tahun $<$ Usia $\leq 40$ tahun & 33 & $33 \%$ \\
\hline 40 tahun $<$ Usia $\leq 50$ tahun & 22 & $22 \%$ \\
\hline$>50$ tahun & 12 & $12 \%$ \\
\hline \multicolumn{3}{|c|}{ Jenis Kelamin } \\
\hline Laki - laki & 63 & $63 \%$ \\
\hline Perempuan & 37 & $37 \%$ \\
\hline \multicolumn{3}{|l|}{ Pekerjaan } \\
\hline Pelajar & 15 & $15 \%$ \\
\hline PNS / Pegawai BUMN / ABRI & 17 & $17 \%$ \\
\hline Pegawai Swasta & 11 & $11 \%$ \\
\hline Wiraswasta & 25 & $25 \%$ \\
\hline Ibu rumah tangga & 2 & $2 \%$ \\
\hline Bercocok tanam & 27 & $27 \%$ \\
\hline Lainnya & 3 & $3 \%$ \\
\hline
\end{tabular}

\begin{tabular}{|c|c|c|}
\hline Profil & Jumlah & Persentase \\
\hline \multicolumn{3}{|c|}{ Uang saku } \\
\hline Uang saku $\leq \mathrm{Rp} 1,5$ juta & 4 & $4 \%$ \\
\hline 1,5 juta $<$ uang saku $<3$ juta & 6 & $6 \%$ \\
\hline 3 juta $<$ uang saku $<5$ juta & 3 & $3 \%$ \\
\hline 5 juta $<$ uang saku $<7$ juta & 1 & $1 \%$ \\
\hline$>7$ juta & 1 & $1 \%$ \\
\hline \multicolumn{3}{|c|}{ Penghasilan } \\
\hline Penghasilan $\leq 2,5$ juta & 28 & $28 \%$ \\
\hline 2,5 juta $<$ penghasilan $<4$ juta & 18 & $18 \%$ \\
\hline 4 juta $<$ penghasilan $<6$ juta & 14 & $14 \%$ \\
\hline 6 juta $<$ penghasilan $<10$ juta & 11 & $11 \%$ \\
\hline 10 juta $<$ penghasilan $<15$ juta & 9 & $9 \%$ \\
\hline$>15$ juta & 5 & $5 \%$ \\
\hline \multicolumn{3}{|l|}{ Merk } \\
\hline Yamaha & 42 & $42 \%$ \\
\hline Honda & 31 & $31 \%$ \\
\hline Suzuki & 12 & $12 \%$ \\
\hline Piaggio & 4 & $4 \%$ \\
\hline Kawasaki & 6 & $6 \%$ \\
\hline Lainnya & 5 & $5 \%$ \\
\hline
\end{tabular}


Tabel 4. Profil Konsumen (Lanjutan)

\begin{tabular}{|c|c|c|c|c|c|}
\hline Profil & Jumlah & Persentase & Profil & Jumlah & Persentase \\
\hline \multicolumn{3}{|c|}{ Pendidikan } & \multicolumn{3}{|c|}{ Jenis Motor Yang Anda Inginkan } \\
\hline Tidak sekolah & 11 & $11 \%$ & Standar / motor bebek & 41 & $41 \%$ \\
\hline SD / Sederajat & 24 & $24 \%$ & Motor Matic & 37 & $37 \%$ \\
\hline SMP / Sederajat & 18 & $18 \%$ & Motor Sport $(150-250 \mathrm{cc})$ & 12 & $12 \%$ \\
\hline SMA / Sederajat & 17 & $17 \%$ & \multirow{2}{*}{$\begin{array}{l}\text { Motor CBU / Completely Build UP } \\
\text { (diatas } 600 \mathrm{cc} \text { ) }\end{array}$} & \multirow{2}{*}{2} & \multirow{2}{*}{$2 \%$} \\
\hline Diploma & 15 & $15 \%$ & & & \\
\hline Sarjana & 10 & $10 \%$ & Lainnya & 8 & $8 \%$ \\
\hline Magister / Doktor & 5 & $5 \%$ & \multicolumn{3}{|c|}{ Uang muka yang diinginkan } \\
\hline Lainnya & 0 & $0 \%$ & 1 juta $<$ uang muka $\leq 2$ juta & 40 & $40 \%$ \\
\hline \multicolumn{3}{|c|}{ Motivasi membeli Motor } & 2 juta $<$ uang muka $\leq 5$ juta & 29 & $29 \%$ \\
\hline Gaya hidup & 5 & $5 \%$ & 5 juta $<$ uang muka $\leq 7$ juta & 16 & $16 \%$ \\
\hline \multirow{2}{*}{$\begin{array}{l}\text { Kebanggaan dan ajang } \\
\text { sosialisasi }\end{array}$} & \multirow{2}{*}{10} & \multirow{2}{*}{$10 \%$} & 7 juta $<$ uang muka $\leq 9$ juta & 8 & $8 \%$ \\
\hline & & & 9 juta $<$ uang muka $\leq 11$ juta & 5 & $5 \%$ \\
\hline Komunitas & 6 & $6 \%$ & $>11$ juta & 2 & $2 \%$ \\
\hline Mempercepat jarak tempuh & 17 & $17 \%$ & \multicolumn{3}{|c|}{ Kartu kredit yang digunakan } \\
\hline Pekerjaan & 34 & $34 \%$ & $\mathrm{BCA}$ & 9 & $9 \%$ \\
\hline Penunjang aktivitas & 28 & $28 \%$ & MANDIRI & 5 & $5 \%$ \\
\hline \multicolumn{3}{|c|}{ Cara Pembayaran } & HSBC & 3 & $3 \%$ \\
\hline Debit & 22 & $22 \%$ & NIAGA & 2 & $2 \%$ \\
\hline Kredit & 24 & $24 \%$ & BNI & 1 & $1 \%$ \\
\hline Tunai & 54 & $54 \%$ & Lainnya & 4 & $4 \%$ \\
\hline \multicolumn{3}{|c|}{ Kartu debit yang digunakan } & \multicolumn{3}{|c|}{ Cicilan motor yang diinginkan } \\
\hline $\mathrm{BCA}$ & 7 & $7 \%$ & $<1$ juta & 58 & $58 \%$ \\
\hline MANDIRI & 6 & $6 \%$ & 1 juta $<$ cicilan $\leq 2$ juta & 20 & $20 \%$ \\
\hline HSBC & 4 & $4 \%$ & 2 juta $<$ cicilan $\leq 3$ juta & 12 & $12 \%$ \\
\hline NIAGA & 3 & $3 \%$ & 3 juta $<$ cicilan $\leq 4$ juta & 3 & $3 \%$ \\
\hline $\mathrm{BNI}$ & 1 & $1 \%$ & 4 juta $<$ cicilan $\leq 5$ juta & 2 & $2 \%$ \\
\hline Lainnya & 1 & $1 \%$ & $>5$ juta & 5 & $5 \%$ \\
\hline \multicolumn{3}{|c|}{ Media informasi promosi mengenai motor } & \multicolumn{3}{|c|}{ Media cetak yang disukai } \\
\hline Sales & 48 & $48 \%$ & Brosur & 40 & $40 \%$ \\
\hline Media Social & 5 & $5 \%$ & Koran & 18 & $18 \%$ \\
\hline Radio & 7 & $7 \%$ & Pamflet & 16 & $16 \%$ \\
\hline Media Cetak & 30 & $30 \%$ & Artikel Produk & 10 & $10 \%$ \\
\hline Website & 4 & $4 \%$ & Majalah & 16 & $16 \%$ \\
\hline Lainnya & 6 & $6 \%$ & Lainnya & 0 & $0 \%$ \\
\hline \multicolumn{3}{|c|}{ Majalah yang sering dibaca } & \multicolumn{3}{|c|}{ Koran yang sering dibaca } \\
\hline Tempo & 0 & $0 \%$ & Pikiran Rakyat & 3 & $3 \%$ \\
\hline Trubus & 0 & $0 \%$ & Kompas & 2 & $2 \%$ \\
\hline Otomotif & 1 & $1 \%$ & Tempo & 1 & $1 \%$ \\
\hline Magle & 2 & $2 \%$ & Sipatuhanan & 5 & $5 \%$ \\
\hline Cupumanik & 5 & $5 \%$ & Galura & 4 & $4 \%$ \\
\hline Lainnya & 8 & $8 \%$ & Lainnya & 3 & $3 \%$ \\
\hline
\end{tabular}


Tabel 4. Profil Konsumen (Lanjutan)

\begin{tabular}{|c|c|c|}
\hline Profil & Jumlah & Persentase \\
\hline \multicolumn{3}{|c|}{ Media Sosial } \\
\hline Twitter & 3 & $3 \%$ \\
\hline Facebook & 2 & $2 \%$ \\
\hline Path & 0 & $0 \%$ \\
\hline Instagram & 0 & \\
\hline Pinterest & 0 & $0 \%$ \\
\hline Lainnya & 0 & $0 \%$ \\
\hline \multicolumn{3}{|c|}{ Lokasi atau acara yang pernah dikunjungi } \\
\hline Mall & 9 & $9 \%$ \\
\hline Konser Musik & 15 & $15 \%$ \\
\hline CFD ( Car Free Day) & 24 & $24 \%$ \\
\hline Graha Siliwangi & 26 & $26 \%$ \\
\hline Acara Perlombaan & 20 & $20 \%$ \\
\hline Lainnya & 6 & $6 \%$ \\
\hline \multicolumn{3}{|c|}{ Acara yang didengarkan di radio } \\
\hline Berita & 20 & $20 \%$ \\
\hline Lagu & 18 & $18 \%$ \\
\hline Kisah Misteri & 8 & $8 \%$ \\
\hline Acara Sunda & 25 & $25 \%$ \\
\hline Budaya & 18 & $18 \%$ \\
\hline Lainnya & 11 & $11 \%$ \\
\hline
\end{tabular}

\begin{tabular}{|l|r|r|}
\hline \multicolumn{1}{|c|}{ Profil } & Jumlah & Persentase \\
\hline \multicolumn{2}{|c|}{ Radio yang sering didengarkan } \\
\hline Dahlia & 12 & $12 \%$ \\
\hline Cosmo & 18 & $18 \%$ \\
\hline Elshinta & 23 & $23 \%$ \\
\hline RRI & 25 & $25 \%$ \\
\hline Hits & 5 & $5 \%$ \\
\hline Lainnya & 17 & $17 \%$ \\
\hline \multicolumn{3}{|c|}{ Waktu mendengarkan radio } \\
\hline (Pk. 6.00-8.00 ) & 9 & $9 \%$ \\
\hline (Pk. 10.00-12.00) & 22 & $22 \%$ \\
\hline (Pk. 13.00-15.00 ) & 25 & $25 \%$ \\
\hline (Pk. 16.00-18.00 ) & 26 & $26 \%$ \\
\hline (Pk. 18.00-20.00) & 10 & $10 \%$ \\
\hline Lainnya & 8 & $8 \%$ \\
\hline
\end{tabular}

Tabel persentase diatas digunakan untuk membantu PT. Antar Putra Motor memilih target pasar dan menyusun strategi promosi. Berdasarkan tabel diatas, disarankan PT. Antar Putra Motor memilih target konsumen berusia 30 tahun $<$ usia $\leq 50$ tahun, pekerjaan bercocok tanam dan wiraswasta, uang saku pelajar/mahasiswa Rp. 1.5 juta ke bawah, penghasilan Rp. 6 juta ke bawah, motivasi membeli motor untuk pekerjaan dan penunjang aktivitas, motor yang diinginkan standar dan matic, cara pembayaran tunai, uang muka yang diinginkan 1 juta $<$ uang muka $\leq 2$ juta, cicilan motor yang diinginkan $<1$ juta, informasi mengenai motor diperoleh dari sales dan media cetak, menyukai media cetak brosur, membacaTabloid Galura, koran Galura dan koran Sipatuhanan, menggunakan facebook dan twitter, mendengarkan radio RRI dan Elshinta yaitu acara berbahasa sunda dan berita, mendengarkan radio sekitar pukul pk. 10.00-18.00.

\subsubsection{Pengujian Importance-Performance Analysis (IPA)}

Metode IPA digunakan untuk mengetahui prioritas perbaikan yang dilakukan oleh perusahaan, melalui kuadran dari masing-masing variabel. Kuadran terbentuk dari nilai rata-rata tingkat kinerja (sumbu X) dan nilai rata-rata tingkat kepentingan (sumbu Y) dari keenam variabel Bauran Promosi hasil validasi.

Tabel 5. Nilai Tingkat Kinerja dan Tingkat Kepentingan

\begin{tabular}{|c|c|c|c|}
\hline Variabel & No. koordinat & Nilai Kinerja (X) & Nilai Kepentingan $(\mathrm{Y})$ \\
\hline 4 & 1 & 2.880 & 3.410 \\
\hline 12 & 2 & 2.830 & 3.440 \\
\hline 21 & 3 & 3.400 & 3.440 \\
\hline 22 & 4 & 3.400 & 3.480 \\
\hline 25 & 5 & 3.240 & 3.460 \\
\hline \multirow[t]{2}{*}{33} & 6 & 3.350 & 3.370 \\
\hline & Rata-rata & 3.183 & 3.433 \\
\hline
\end{tabular}




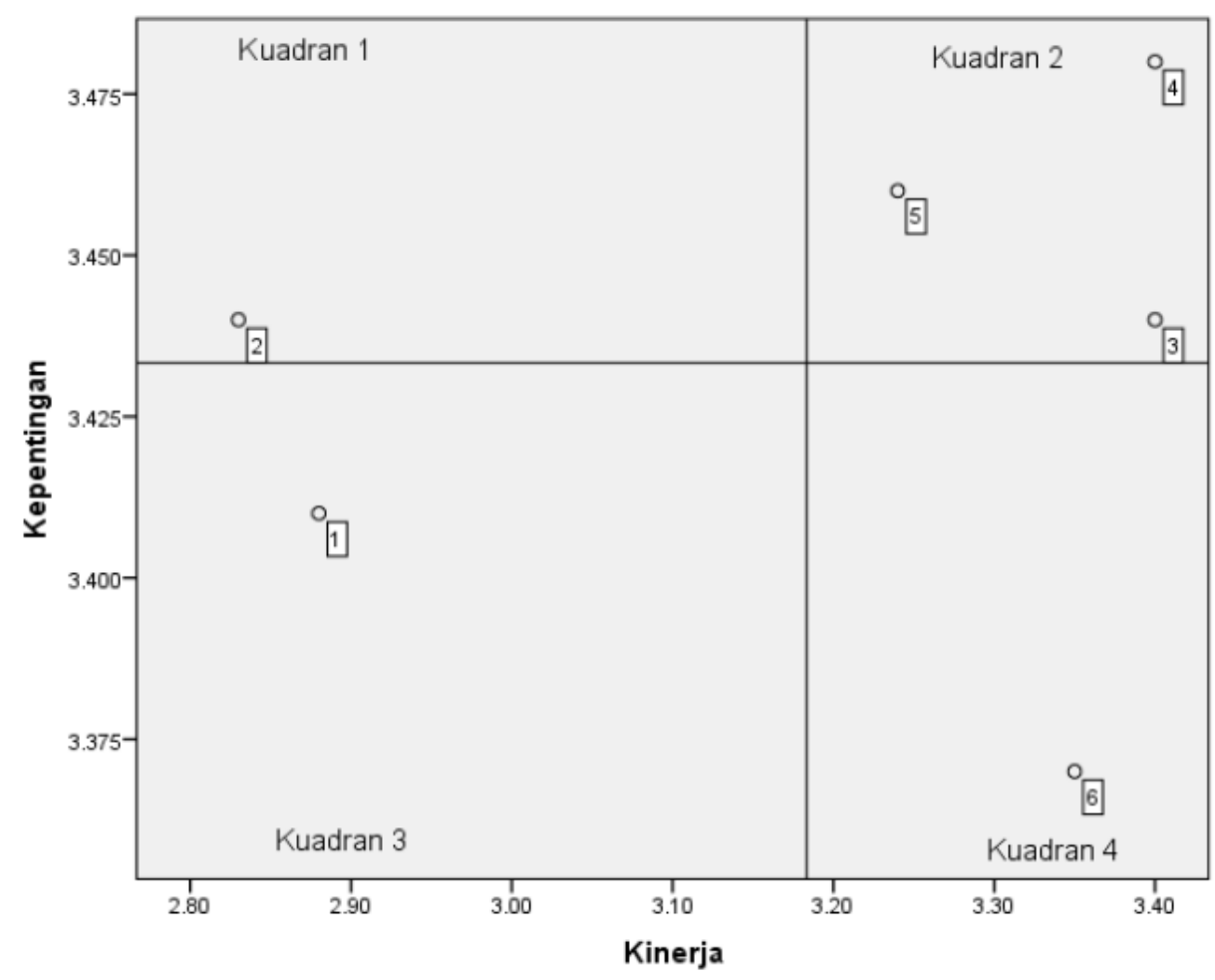

Gambar 2. Matriks Importance-Performance Analysis

Variabel yang membutuhkan prioritas perbaikan berdasarkan IPA adalah variabel yang berada pada kuadran 1 karena variabel ini memiliki nilai kinerja di bawah rata-rata padahal nilai kepentingan konsumen diatas rata-rata, yaitu nomor koordinat 2 (Var 12): Kekontrasan warna yang digunakan (media cetak ). Prioritas perbaikan selanjutnya adalah variabel pada kuadran 3, karena walaupun nilai kepentingannya dibawah rata-rata namun masih diatas 3, yaitu nomor koordinat 1 (Var 4): Kemenarikan kata - kata yang digunakan di majalah. Kemudian perbaikan selanjutnya difokuskan pada variabel di kuadran 2, yaitu Var 21, 22, 25 (Kemenarikan pemberian diskon oleh PT. Antar Putra Motor setiap penjualan, Cash back dengan jumlah besar pada pertengahan tahun dan akhir tahun, Kesempatan yang diberikan oleh PT. Antar Putra Motor untuk melakukan kunjungan Ke PT. Antar Putra Motor ). Perbaikan terakhir pada variabel di kuadran 4 yaitu Var 33 (Kemampuan SPG untuk menjelaskan produk).

\subsubsection{Pengujian Hipotesis Rata-rata}

Pengujian hipotesis pada keenam variabel Bauran Promosi hasil validasi, dengan tujuan untuk mengetahui apakah terjadi kesenjangan antara tingkat kepentingan konsumen dan kinerja yang diberikan oleh PT. Antar Putra Motor.

Struktur Hipotesis:

Ho : $\mu_{1}=\mu_{2}$

(tidak ada perbedaan antara tingkat kinerja PT. Antar Putra Motor dengan tingkat kepentingan, sehingga konsumen puas)

Hi $\quad: \mu_{1}<\mu_{2}$ (tingkat kinerja PT. Antar Putra Motor lebih rendah daripada tingkat kepentingan,

Keterangan : sehingga konsumen tidak puas)

Sampel 1 : tingkat kinerja

Sampel 2 : tingkat kepentingan

Taraf nyata: $\alpha=0.05$ 
Statistik uji: Uji Normal

$$
Z_{\text {hitung }}=\mathrm{Z}=\frac{\left(\overline{\mathrm{x}}_{1}-\overline{\mathrm{x}}_{2}\right)-\left(\mu_{1}-\mu_{2}\right)}{\sqrt{\frac{\mathrm{s}_{1}^{2}}{\mathrm{n}_{1}}+\frac{\mathrm{s}_{2}^{2}}{\mathrm{n}_{2}}}}=\frac{(2.880-3.410)-(0)}{\sqrt{\frac{0.537}{100}+\frac{0.637}{100}}}=-4.891
$$

Wilayah Kritis : dari tabel distribusi Normal dengan $\alpha=0.05=-1.645$

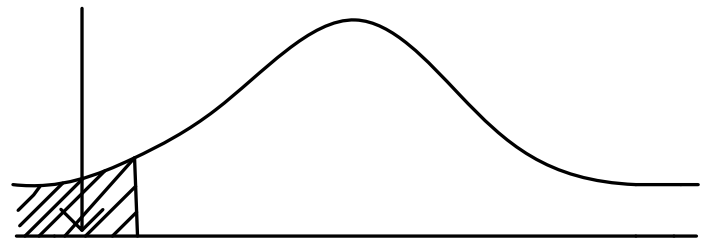

$-1.645$

Keputusan:

Gambar 3. Wilayah Kritis Uji Normal

Jika hasil $\mathrm{Z}$ hitung > dari $\mathrm{Z}$ tabel maka terima $\mathrm{H}_{0}$, konsumen PT. Antar Putra Motor merasa puas, dan sebaliknya.

Tabel 6. Hasil Pengujian Hipotesis Rata-rata

\begin{tabular}{|c|c|c|c|c|c|c|c|}
\hline \multirow{2}{*}{ Var } & \multicolumn{2}{|c|}{ Kinerja } & \multicolumn{2}{c|}{ Kepentingan } & \multirow{2}{*}{$\mathrm{Z}$} & Keputusan & Kesimpulan \\
\cline { 2 - 5 } & $\begin{array}{c}\text { Rata- } \\
\text { rata }\end{array}$ & Variansi & $\begin{array}{c}\text { Rata- } \\
\text { rata }\end{array}$ & Variansi & hitung & Kepus & Konsumen Tidak Puas \\
\hline 4 & 2.880 & 0.537 & 3.410 & 0.637 & -4.891 & Tolak Ho & Konsumen Tidak Puas \\
\hline 12 & 2.830 & 0.587 & 3.440 & 0.625 & -5.542 & Tolak Ho & Konsun \\
\hline 21 & 3.400 & 0.620 & 3.440 & 0.556 & -0.369 & Terima Ho & Konsumen Puas \\
\hline 22 & 3.400 & 0.667 & 3.480 & 0.559 & -0.723 & Terima Ho & Konsumen Puas \\
\hline 25 & 3.240 & 0.683 & 3.460 & 0.626 & -1.922 & Tolak Ho & Konsumen Tidak Puas \\
\hline 33 & 3.350 & 0.796 & 3.370 & 0.614 & -0.168 & Terima Ho & Konsumen Puas \\
\hline
\end{tabular}

Hasil pengujian hipotesis rata-rata diatas menunjukkan bahwa dari 6 variabel Bauran Promosi, hanya separuhnya (3 variabel) yang telah memuaskan konsumen. Perbaikan akan berfokus pada variabel yang paling belum memuaskan konsumen, yaitu Var 12, dengan nilai Z hitung terendah

\subsubsection{Penentuan Prioritas Perbaikan}

Perbaikan dilakukan pada 6 variabel bauran pemasaran hasil validasi. Prioritas perbaikan diberikan berdasarkan penggabungan hasil pengolahan Importance Performance Analysis dan pengujian hipotesis rata-rata.

Tabel 7. Prioritas Perbaikan

\begin{tabular}{|c|c|c|c|c|c|}
\hline \multirow{2}{*}{\multicolumn{2}{|c|}{ Variabel }} & \multirow{3}{*}{$\begin{array}{c}\text { Kuadran } \\
\text { IPA }\end{array}$} & \multicolumn{2}{|c|}{ Pengujian Hipotesis } & \multirow{3}{*}{$\begin{array}{c}\begin{array}{c}\text { Prioritas } \\
\text { Perbaikan }\end{array} \\
1\end{array}$} \\
\hline & & & Z hitung & Keputusan & \\
\hline 12 & Kekontrasan warna yang digunakan (media cetak) & & -5.542 & Tidak puas & \\
\hline 4 & Kemenarikan kata - kata yang digunakan di majalah & 3 & -4.891 & Tidak puas & 2 \\
\hline 25 & $\begin{array}{l}\text { Kesempatan yang diberikan oleh PT. Antar Putra } \\
\text { Motor untuk melakukan kunjungan Ke PT. Antar } \\
\text { Putra Motor }\end{array}$ & 2 & -1.922 & Tidak puas & 3 \\
\hline 22 & $\begin{array}{l}\text { Cash back dengan jumlah besar pada pertengahan } \\
\text { tahun dan akhir tahun }\end{array}$ & 2 & -0.723 & Puas & 4 \\
\hline 21 & $\begin{array}{l}\text { Kemenarikan pemberian diskon oleh PT. Antar } \\
\text { Putra Motor setiap penjualan }\end{array}$ & 2 & -0.369 & Puas & 5 \\
\hline 33 & Kemampuan SPG untuk menjelaskan produk & 4 & -0.168 & Puas & 6 \\
\hline
\end{tabular}




\section{Kesimpulan dan Saran}

1. Penelitian ini bertujuan untuk meningkatkan penjualan di PT. Antar Putra Motor dengan menggunakan teori bauran promosi dan STP.

2. Berdasarkan profil konsumen, disarankan agar PT. Antar Putra Motor memilih target konsumen berusia 30 tahun $<$ usia $\leq 50$ tahun, pekerjaan bercocok tanam dan wiraswasta, uang saku pelajar/mahasiswa Rp. 1.5 juta ke bawah, penghasilan Rp. 6 juta ke bawah, motivasi membeli motor untuk pekerjaan dan penunjang aktivitas, motor yang diinginkan standar dan matic, cara pembayaran tunai, uang muka yang diinginkan 1 juta $<$ uang muka $\leq 2$ juta, cicilan motor yang diinginkan $<1$ juta, informasi mengenai motor diperoleh dari salesman dan media cetak, menyukai media cetak brosur, membacaTabloid Galura, koran Galura dan koran Sipatuhanan, menggunakan facebook dan twitter, mendengarkan radio RRI dan Elshinta yaitu acara berbahasa sunda dan berita, mendengarkan radio sekitar pukul pk. 10.00-18.00.

3. Hasil validasi menggunakan metode Analisis Faktor menghasilkan 6 variabel bauran promosi yaitu Kemenarikan kata-kata yang digunakan di majalah (Var 4), Kekontrasan warna yang digunakan (media cetak) (Var 12), Kemenarikan pemberian diskon oleh PT. Antar Putra Motor setiap penjualan (Var 21), Cash back dengan jumlah besar pada pertengahan tahun dan akhir tahun (Var 22), Kesempatan yang diberikan oleh PT. Antar Putra Motor untuk melakukan kunjungan Ke PT. Antar Putra Motor (Var 25), dan Kemampuan SPG untuk menjelaskan produk (Var 33).

4. PT. Antar Putra Motor dapat meningkatkan penjualan dengan melakukan strategi promosi, sesuai prioritas perbaikan yang diperoleh melalui penggabungan hasil pengolahan IPA dan pengujian hipotesis rata-rata. Berikut prioritas strategi promosi yang dihasilkan dari penelitian:

a. Prioritas 1: Kekontrasan warna yang digunakan (media cetak) (Var 12)

b. Prioritas 2: Kemenarikan kata-kata yang digunakan di majalah (Var 4).

c. Prioritas 3: Kesempatan yang diberikan oleh PT. Antar Putra Motor untuk melakukan kunjungan Ke PT. Antar Putra Motor (Var 25),

d. Prioritas 4: Cash back dengan jumlah besar pada pertengahan tahun dan akhir tahun (Var 22)

e. Prioritas 5: Kemenarikan pemberian diskon oleh PT. Antar Putra Motor setiap penjualan (Var 21)

f. Prioritas 6: Kemampuan SPG untuk menjelaskan produk (Var 33)

g. Target konsumen mendapatkan informasi mengenai motor melalui salesman (40\%), karenanya pihak perusahaan harus mempersiapkan SPGnya dengan informasi tentang spesifikasi setiap motor yang dijualnya. Para SPG perlu dilatih kemampuan komunikasi dan ramah agar konsumen tertarik dengan produk yang ditawarkan.

5. Usulan bagi PT. Antar Putra Motor:

a. Target konsumen menyukai media cetak brosur (40\%), sehingga perlu dilakukan penelitian lebih lanjut mengenai pemilihan warna yang tepat dan kekontrasan warna untuk media cetak terutama brosur. Pihak perusahaan harus memilih kualitas kertas yang baik untuk brosur agar warna yang digunakan dapat terlihat bagus.

b. Pihak perusahaan perlu memilih poin-poin penting yang merupakan fokus bagi konsumen agar pembaca tidak bosan membaca kata-kata promosi yang terlalu panjang. Dapat dipertimbangkan menggunakan kata-kata yang unik atau lucu bagi orang dewasa sesuai target konsumen 30 tahun $<$ usia $\leq 50$ tahun (33\%), atau menggunakan kata-kata berbahasa Sunda, mengingat mayoritas konsumen menyukai acara berbahasa Sunda $(25 \%)$.

c. Pihak perusahaan perlu menyiapkan karyawan khusus yang bertugas untuk menangani kunjungan dari pihak umum, misalnya untuk kerja magang, tugas akhir mahasiswa, kegiatan edukasi siswa atau karyawan lain. Dengan adanya karyawan yang khusus menangani maka karyawan tersebut akan lebih mahir dan terampil. Kesempatan untuk kunjungan ini dapat diinformasikan pada konsumen melalui berbagai media yang banyak digunakan oleh konsumen yaitu brosur (40\%), radio RRI (25\%) atau Elshinta (23\%) sekitar pukul pk. 10.00-18.00 (73\%), atau pada pameran (26\%) dan acara car free day (24\%).

d. Mayoritas pekerjaan responden adalah bercocok tanam (27\%), sebaiknya perusahaan menyesuaikan tanggal akan diadakannya promosi cash back, yang disesuaikan dengan masa panen para petani. Informasi mengenai diadakannya cashback perlu dilakukan 
melalui berbagai media yang banyak digunakan oleh konsumen yaitu brosur (40\%), radio RRI (25\%) atau Elshinta (23\%) sekitar pukul pk. 10.00-18.00 (73\%), atau pada pameran (26\%) dan acara car free day (24\%).

e. Target konsumen menyukai cara pembayaran tunai (54\%) sehingga perusahaan disarankan untuk memberikan diskon tambahan bagi pembelian tunai. Untuk pembelian secara kredit dan debit, perusahaan dapat bekerjasama dengan beberapa bank terutama bank BCA yang banyak digunakan konsumen $(9 \%)$ untuk pemberian diskon. Informasi mengenai pemberian diskon ini dapat dilakukan melalui berbagai media yang banyak digunakan oleh konsumen yaitu brosur (40\%), radio RRI (25\%) atau Elshinta (23\%) sekitar pukul pk. $10.00-18.00(73 \%)$, atau pada pameran (26\%) dan acara car free day (24\%).

\section{Daftar Pustaka}

Anderson, D., Sweeney, D.J., Williams, T.A. (2008), "Statistics for Business \& Economics", $10^{\text {th }}$ edition, Thomson South-Western.

Hair, Anderson, Tatham \& Black (2006), "Multivariate Data Analysis", Prentice-Hall International, Inc., USA.

Herlinmanda, C.D., Yulianti (2018), "Usulan Strategi Pemasaran bagi CDCmodels untuk Memenangkan Persaingan Onlineshop", Journal of Integrated System Vol 1 Issue 1, 105-127.

Kotler, P. (1997), “Manajemen Pemasaran”, Jilid 2, Edisi Kesembilan, PT. Prehallindo.

Sugiyono (2010), “Metode Penelitian Administrasi”, CV. ALFABETA, Bandung.

Supranto, J. (2001), “Pengukuran Tingkat Kepuasan Pelanggan”, PT Rineka Cipta, Jakarta. 